\title{
MODULAÇÕES DA SUBJETIVIDADE CONTEMPORÂNEA: ficção científica e objetos técnicos
}

\author{
Fátima Regis ${ }^{1}$
}

Resumo: O texto discute como objetos técnicos e ficção científica modulam as subjetividades contemporâneas. Parte do advento do computador que gera um meio de comunicação singular. A seguir mostra como as mídias digitais promovem a comunicação multimodal e mobilizam um conjunto de habilidades sensoriais, criativas e de teamworking, desafiando o conceito de inteligência. Recorre-se ao conceito de cognição atuada (VARELA, 1990) para compreender essa inteligência que envolve corpo, afetos e sociabilidade. Ao desafiar as fronteiras entre corpo/mente, natureza/técnica, interior/exterior, a cognição atuada fornece pistas para entendermos porque nossos gadgets dão a sensação de estarmos imersos em histórias de ficção científica, modulando nossa subjetividade com outras possibilidades de nós mesmos.

Palavras-chaves: Objetos técnicos, inteligência, ficção científica, subjetividade, cognição.

\begin{abstract}
The paper discusses how technical objects and science fiction modulate contemporary subjectivities. The text begins with an analysis of how computer inaugurates a unique medium of communication. Then it demonstrates how digital media promote multimodal communication and mobilize a set of sensory skills, creative and teamworking, challenging the concept of intelligence. The paper refer to the concept of enaction (VARELA, 1990) to understand that intelligence involves body, affection and sociability. By challenging the boundaries between body/mind, nature/technique, interior/exterior, the enaction provides clues to understand why our gadgets give the feeling of being immersed in science fiction stories, modulating our subjectivity with other possibilities for ourselves.
\end{abstract}

Keywords: Technical objects, intelligence, science fiction, subjectivity, cognition.

\section{Introdução}

Abordar as questões propostas pelo Seminário “Objetos Técnicos, Ficção Científica e Transformação Social" foi um convite para nos interrogamos sobre como pensar as modulações da subjetividade nesses tempos de simetria entre humanos e não-humanos, em que nossos gadgets são mais futurísticos do que aqueles saídos dos livros e filmes de ficção científica. Nesse sentido, cabe esclarecer que o conceito de subjetividade ou processos de subjetivação que orienta este texto se alinha com o de Félix Guattari (1992). O pensador destaca o modo como a subjetividade se modula nas acoplagens entre instâncias individuais e coletivas, por meio de agentes humanos e não-humanos, articulando-se a fatores materiais e incorporais, tais como os de expressões linguísticas e artísticas. Nas palavras de Guattari, processos de subjetivação são:

${ }^{1}$ Professora da Faculdade de Comunicação Social da UERJ, onde leciona na graduação e no Programa de PósGraduação em Comunicação. É Pesquisadora do CNPq e do Prociência (UERJ/FAPERJ). Escreveu o livro "Nós, ciborgues: tecnologias da informação e subjetividade homem-máquina (Champagnat, 2012). 
o conjunto das condições que torna possível que instâncias individuais e/ou coletivas estejam em posição de emergir como território existencial auto-referencial, em adjacência ou em relação de delimitação com uma alteridade ela mesma subjetiva. (...) Assim, em certos contextos sociais e semiológicos, a subjetividade se individua... Em outras condições, a subjetividade se faz coletiva. (...) As condições de produção evocadas nesse esboço de redefinição implicam, então, conjuntamente, instâncias humanas intersubjetivas manifestadas pela linguagem e instâncias sugestivas ou identificatórias concernentes à etologia, interações institucionais de diferentes naturezas, dispositivos maquínicos, tais como aqueles que recorrem ao trabalho com computador, Universos de referência incorporais, tais como aqueles relativos à música e às artes plásticas” (GUATTARI, 1992, p. 19-20).

Temos uma longa tradição em investigar os modos como objetos técnicos se articulam com processos de subjetivação. O antropólogo e arqueólogo André Leroi-Gourhan (1945), por meio de pesquisa empírica, mostra como a área motora do córtex está interligada à da linguagem, reflexo de um processo evolutivo que começa com a transição para a postura bípede. Segundo o autor, essa mudança teria permitido a liberação das mãos para fabricar utensílios e para a gestualidade, favorecendo assim o desenvolvimento de habilidades simbólicas, de linguagem e de técnica. Assim as inovações técnicas articuladas aos processos biológicos produziram inteligência, em uma evolução que teria ocorrido há um milhão de anos. Autores como Scott Bukatman e Bruce Mazlish defendem que a produção de ferramentas como modo de interagir com o ambiente é definidora de nossa espécie. Bukatman sugere que as novas concepções de humano devem situar homens e tecnologia como coextensivos, co-dependentes e definidos mutuamente (1998, p. 22). Mazlish revela que sob os questionamentos atuais sobre a natureza do humano e da técnica reside um longo percurso de co-evolução entre os homens e seus objetos técnicos (1993, p. 10).

No presente texto, pretendemos nos dedicar às Tecnologias da Informação e da Comunicação (TIC). Para investigarmos os processos subjetivos implicados com as mudanças tecnológicas contemporâneas, o ponto de partida da análise será o momento do pós-guerra período de invenção do computador. Em seguida, mostraremos como as mídias e redes digitais promovem a comunicação multimodal e mobilizam um conjunto de habilidades sensoriais, criativas e de teamworking, desafiando o conceito de inteligência. Como essas habilidades implicam uma articulação inextricável entre corpo e ambiente (incluídas aqui as afetividades, sociabilidades e interações com os objetos técnicos), as modulações subjetivas contemporâneas também problematizam as fronteiras entre interior e exterior, mente e corpo, orgânico e maquínico. Na busca por compreender as subjetivações entre agentes humanos e não-humanos num processo que articula de modo inextricável corpo, técnica e cultura, 
recorremos ao conceito de cognição atuada² de Francisco Varela (1990). Por sua abordagem transdisciplinar, a cognição atuada fornece pistas para entendermos porque as narrativas de ficção científica, com suas histórias sobre outros seres (robôs, mutantes, alienígenas) e outros tempos e espaços (histórias alternativas, planetas longínquos, interior da Terra), são tão férteis para problematizar a subjetividade contemporânea.

\section{Computadores e redes: de dispositivos de computação a dispositivos de comunicação}

O computador foi inventado durante a Segunda Guerra Mundial com propósitos militares. Os esforços dos primeiros anos da computação eram aplicados na realização de cálculos de artilharia para as tropas aliadas quebrarem os códigos da comunicação criptografada dos adversários. Os alemães haviam criado uma máquina - Enigma - para cifrar suas mensagens. A Enigma gerava códigos novos a cada mensagem, tornando o esforço dos serviços de contra-espionagem dos aliados quase inútil: quando um código terminava de ser decifrado, já não era mais utilizado.

Na tentativa de superar os alemães, os ingleses se basearam nas teorias de computação de Alan Turing e construíram Colossus - uma máquina que explorava todas as alternativas possíveis a partir de uma variável. Nos Estados Unidos, Vanevar Bush trabalhava na construção do Memex (um arquivo complexo que disporia de todo o conhecimento produzido pelo ser humano), enquanto John von Neumann e outros cientistas trabalhavam na construção do ENIAC que, lançado em 1946, inaugurou a primeira geração dos computadores eletrônicos.

Como a máquina que calculava tomava como ponto de partida o cérebro humano, os pesquisadores se inspiravam na inteligência humana para pensar os dispositivos computacionais. No entanto, o conceito de inteligência aplicado era o de uma inteligência racional, lógica, descorporificada. Como Katherine Hayles ressalta - referindo-se ao Teste de Turing $^{3}$-, na inauguração da era do computador, a inteligência é definida como capacidade de

\footnotetext{
${ }^{2}$ Adotamos a proposta de Virgínia Kastrup (2007) de traduzir o termo enaction utilizado por Varela (1990) por atuação, daí cognição atuada.

${ }^{3}$ Em 1936, Alan Turing utilizou os recentes estudos de lógica formal em termos matemáticos para descrever o funcionamento da Máquina de Turing - uma máquina universal ideal muito simples, que abstrai as limitações físicas (tempo de execução, limitação de memória, rapidez dos componentes da máquina). Em 1950 o
} 
manipulação formal de símbolos, sem referência a características físicas e atuação no mundo humano (1999, p. xi).

A primeira onda da Inteligência Artificial, associada à criação da Cibernética, teve o grande mérito de problematizar as fronteiras entre organismos vivos e maquínicos. Porém, a ênfase dada pelos pesquisadores da cibernética ao conceito de informação como entidade abstrata e primordial na organização dos sistemas vivos e maquínicos desenfatizou a importância do corpo e do ambiente/contexto para os processos cognitivos. Hayles explica:

Tudo o que importava era [...] a manipulação de padrões informacionais. Contribuindo para este processo estava a definição de informação, formalizada por Claude Shannon e Norbert Wiener, que conceituou informação como uma entidade distinta dos substratos que a transportavam. A partir desta formulação, foi um pequeno passo para pensar a informação como uma espécie de fluido sem corpo capaz de fluir entre diferentes substratos sem perda de significado ou de forma ${ }^{4}$. (HAYLES, 1999, p. xi).

Outro fator que contribuiu para a minimizar a importância do corpo e do ambiente foi o fato de que no alvorecer da inteligência artificial os aparatos robóticos criados sobre base material com objetivo de locomoção e exploração do ambiente eram muito dispendiosos e ineficazes. Já os supercomputadores comprovaram de imediato sua incrível capacidade de cálculo e aplicações práticas, razão pela qual nas décadas subsequentes receberam a maior parte dos investimentos para pesquisa.

Apesar da surpreendente capacidade de cálculo, a interação com os supercomputadores era difícil e desinteressante. As máquinas eram gigantescas e pesadas; os dispositivos periféricos, duros e desconfortáveis; os códigos e linguagens de programação, pouco intuitivos e amigáveis. Dadas as grandes dificuldades iniciais de interatividade com as máquinas, não é exagero afirmar que a verdadeira revolução da informática é iniciada menos pela capacidade de cálculo do computador do que pela invenção da interface gráfica. Foram as interfaces que permitiram conexões mais fluidas do computador com o corpo e a mente humana na realização de tarefas sensoriais e cognitivas. Como explica Steven Johnson "É por meio de interfaces que temos acesso às informações contidas nos bancos de dados do

matemático enuncia o que ficou conhecido como Teste de Turing: a máquina é inteligente quando não há diferença discernível entre conversar com ela ou com uma pessoa. TURING, 1990).

${ }^{4}$ Do original: "All that mattered was the [...] manipulation of informational patterns. Aiding this process was a definition of information, formalized by Claude Shannon and Norbert Wiener, that conceptualized information as an entity distinct from the substrates carrying it. From this formulation, it was a small step to think of information as a kind of bodiless fluid that could flow between different substrates without loss of meaning or form”. (Hayles, 1999, p. xi) 
ciberespaço. A interface é o lugar onde ocorre a troca entre domínios heterogêneos e é a própria condição de possibilidade da interação" (2001, p. 23).

Letícia Perani Soares destaca que foram os desenvolvimentos na área de interface gráfica, tais como o Sketchpad de Ivan Sutherland, que dinamizaram a comunicação humanocomputador. A autora destaca a ponderação de Sutherland sobre as possibilidades de seu invento:

\begin{abstract}
O sistema Sketchpad torna possível para um humano e um computador conversarem rapidamente por meio de traços. Antes, a maior parte da interação entre humanos e computadores teve sua velocidade diminuída pela necessidade de reduzir toda a comunicação a instruções escritas que possam ser digitadas (...) O sistema Sketchpad, que elimina instruções digitadas (com exceção de legendas) em favor de traços, abre um novo campo de comunicação humano-máquina. (SUTHERLAND apud SOARES, 2016, p. 8 [grifos nossos]).
\end{abstract}

Soares observa que, ao dar estas capacidades gráficas e interativas ao computador, os desenvolvedores de interface transformaram-no em um poderoso meio de expressão visual, alterando radicalmente os usos e funções pensadas para estes dispositivos: "Se antes os computadores eram simples máquinas de cálculos e processamento de dados, a partir do desenvolvimento das teorias de HCI [interação humano-computador] eles passaram a também ser verdadeiros meios de comunicação" (SOARES, 2016, p. 26 - grifos da autora).

Essa virada de dispositivo de computação para dispositivo de comunicação ganhou solidez em 1968, quando Douglas Engelbart realizou pela primeira vez a façanha de traduzir informação digital (banco de dados) em linguagem visual, projetada na tela. Steven Johnson (2001, p. 22-23) explica que a invenção de Engelbart se deu em duas etapas. A primeira, conhecida como mapeamento de bits (bitmapping) fazia com que cada pequeno naco da memória do computador correspondesse a um pixel na tela. Em seguida, com a invenção do mouse, Engelbart permitiu que nossa ação física (sobre o mouse) correspondesse a um cursor na tela e esta, por sua vez, correspondesse a um lugar no banco de dados, o que ficou chamado de manipulação direta de dados. As interfaces gráficas integradas a janelas de hipertextos e, posteriormente, conectadas em rede deram origem ao ciberespaço. $\mathrm{O}$ ciberespaço é um espaço informacional: “é o espaço de comunicação aberto pela interconexão mundial dos computadores e das memórias dos computadores" (LÉVY, 1999, p. 92). 
No entanto, mesmo com sua capacidade gráfica e possibilidades comunicacionais estabelecidas, a ideia de ciberespaço ainda era difícil de ser assimilada pelo público não especializado.

\section{O ciberespaço da ficção científica: tempo, espaço e experiência subjetiva}

Simulações de computador, janelas de hipertexto e redes como Internet (Arpanet) já existiam, mas foram narrativas de ficção científica como o livro Neuromancer (William Gibson, 1984) e o filme Tron (Disney, 1982) que deram visibilidade e tornaram assimilável o novo espaço de interação informacional.

A sagacidade do escritor de ficção científica William Gibson começa na frase de abertura de sua obra: "O céu por cima do porto tinha a cor de uma TV que saiu do ar" (1991 [1984], p. 13). Na primeira linha de Neuromancer, William Gibson estabelece que não se pode separar a imagem na tela do espaço real, traduzindo de forma notória a imbricação da nova tecnologia com a realidade.

William Gibson conferiu sentido às tecnologias computacionais emergentes. Em Neuromancer, o herói Case tem seus impulsos neurais diretamente conectados ao computador por meio de eletrodos. Katherine Hayles propõe que Gibson criou duas inovações literárias que permitiram a articulação da mente humana diretamente com dados abstratos $(1999$, p. 389). A primeira foi uma modificação sutil na noção de ponto de vista (pov). Na obra, o pov constitui a subjetividade do personagem que funciona como uma marca de posição (na época, cursor; hoje, avatar) que substitui seu corpo ausente. A segunda inovação de Gibson foi transformar a matriz de dados do ciberespaço em um cenário no qual uma história pode se desenvolver. A narrativa torna-se possível quando o pov (avatar) se movimenta pelas paisagens criadas, dotando o ciberespaço de tempo, espaço e experiência subjetiva. A narrativa ficcional traduz o infinito abstrato em termos finitos e assimiláveis pela experiência corporal e cognição sensório-motora. O filme Tron - uma odisseia eletrônica (1982) já havia feito algo similar.

Em Neuromancer, assim como em Tron, o espaço do computador é projetado com a arquitetura das cidades: há vias, meios de transportes para locomoção e sinalização. $\mathrm{O}$ ciberespaço de Gibson tem a forma de megacidades sombrias, superpovoadas, repletas de megacorporações e iluminadas por luzes de néon, recriando o projeto arquitetônico 
conturbado e sombrio das grandes cidades. Por sua vez, as cidades são penetradas pelas novas redes de satélites e terminais de comunicação invisíveis e onipresentes.

Nas obras de ficção científica, espaço físico e informacional se equivalem e se constituem como metáfora um do outro. Neuromancer e Tron capturaram e traduziram para o público a ideia do ciberespaço como um espaço de comunicação, de exploração e de experiência. Na ficção científica, a informação não é incorpórea e o espaço informacional não é meramente um canal que transporta a informação de um ponto a outro, sem alterações. $\mathrm{O}$ meio aqui é ambiência; é condição de produção de sentido, de comunicação e de sociabilidade; é um espaço indissociável da realidade.

Do ponto de vista teórico, o conceito de meio da ficção científica alinha-se com o proposto por Gilbert Simondon em sua teoria do processo de individuação. Em $\mathrm{Du}$ mode d'existence des objets techniques (1980 [1958]), Gilbert Simondon discute a gênese dos objetos técnicos e seu papel na formação da cultura. Em contraposição à abordagem substancialista, Simondon propõe que os indivíduos, sejam eles naturais ou técnicos, nunca apresentam-se em uma configuração definitiva, estão sempre em processo. E essa característica se deve ao papel constituinte do meio na formação do indivíduo. Simondon defende que existe um estágio pré-individual formado pelo par indivíduo-meio que guarda a multiplicidade de potenciais para a individualização. Mesmo após a individualização, esse repertório de possíveis não se esgota, porque a individuação faz aparecer não somente o indivíduo, mas sim a polaridade indivíduo-meio. Assim, o meio nunca é apenas um veículo neutro, é um meio associado que constitui e é constituído pelo indivíduo. "O meio associado é o mediador da relação entre elementos técnicos manufaturados e elementos naturais dentro da qual o ser técnico opera.”. (SIMONDON, 1980, p. 49-50)

\section{Comunicação multimodal: sensorium corporal, ambiência e criação coletiva}

Como vimos acima, com o desenvolvimento das interfaces gráficas e interativas, o computador tornou-se um potente meio de comunicação visual. Com novos avanços que possibilitaram a digitalização - o processo de traduzir para o formato digital conteúdos inicialmente formatados em outras mídias e suportes -, o que era um meio de comunicação inicialmente centrado na expressão visual rapidamente tornou-se também auditivo e tátil, ou seja, um meio de comunicação multimodal. 
A multimodalidade fez do computador o meio de todos os meios: permitiu a assimilação de todos os formatos (orais, impressos, eletrônicos) e linguagens (literárias, radiofônicas, fotográficas, cinematográficas e televisivas) das mídias anteriores. Essa convergência de formatos e linguagens favoreceu os remixes, ou seja, as recombinações e hibridismos de ilustrações, fotos, sons, músicas, animações, filmes e vídeos, gerando a integração de todo tipo de conteúdo. Por sua vez, a miniaturização e barateamento dos gadgets (smartphones, ipads, ipods) e as interfaces amigáveis e intuitivas dos aplicativos digitais facilitou o acesso e o manuseio dos equipamentos, exigindo menos especialização para a produção e distribuição de conteúdos.

Lev Manovich (2005) pondera que na cultura de massa já havia remix, mas, como o manuseio não era tão acessível, o remix era quase que um privilégio do produtor. Na cultura digital a facilidade de acesso e manipulação dos dados por um grande número de usuários permite a remixabilidade colaborativa, que potencializa inovações. Para Manovich, a modulação pós-computador favorece uma maior exploração do meio pelo usuário, o que possibilita o surgimento de hibridismos e acoplagens inusitadas e um estilo de repetição que permite a diversidade.

Por operar com conteúdos baseados em múltiplas linguagens (multimodalidade) as tecnologias digitais exploram nosso rico sensorium corporal, incluindo todo o corpo no processo de produção de sentido. Além de destacar o papel do corpo e da hipermediação, as mídias digitais, distribuídas por inúmeros suportes materiais e plataformas, têm a tendência a gerar uma ambientação que envolve os indivíduos e valoriza o contexto (JOHNSON, 2001, LÉVY, 1999, PEREIRA, 2008). Podemos pensar no jogo Pokémon Go, um jogo de realidade aumentada, no qual o jogador transita entre o espaço da "tela" e o espaço "real", buscando capturar as criaturas pokémons. O jogo insere os pokémons e o avatar do jogador em lugares físicos, como ruas, praças e restaurantes, criando uma espacialidade híbrida entre mundos físicos e informacionais.

Essas experiências que intensificam as sensações corporais e a percepção do ambiente por meio de diferentes estímulos, linguagens e texturas, facilitam a sensação de um estado imersivo pelo indivíduo. A experiência de comunicação é ampliada de uma forma tal que se percebe que a experiência não se resume a uma relação linear de um indivíduo que "recebe" um conteúdo. Em vez disso, o indivíduo faz parte de um processo de produção de conteúdos que envolve agentes humanos (profissionais, amadores, fãs) e agentes não-humanos 
(tecnologias, ferramentas, o ambiente físico, protocolos de uso) funcionando como uma verdadeira rede sociotécnica (Simondon, 1980 [1958]; Latour, 2005). Essa experiência de comunicação e sociabilidade é a de uma fruição que engloba todo um processo de construção e não apenas o consumo de um produto acabado.

O tipo de efervescência sociocultural colocado em prática pela cultura digital estimula a busca e produção de conteúdos, exploração de ambientes híbridos, exigindo um aprendizado contínuo que mobiliza um amplo repertório de habilidades. Para redigir fanfictions, jogar games, produzir vídeos para o YouTube, colaborar em softwares open source, o internauta precisa aprender e incorporar conteúdos, linguagens, softwares, protocolos específicos dos aplicativos e redes digitais; precisa saber remixá-los, compartilhá-los e utilizá-los em diferentes plataformas e suportes. Esses games, aplicativos e sites frequentemente operam em ambientes compartilhados que desafiam as habilidades sociais e afetivas dos jogadores.

Observamos que as práticas comunicativas e sociais da cultura digital têm proporcionado articulações dinâmicas entre humanos, objetos técnicos e ambiente que modulam nossa subjetividade e reconfiguram nossos processos cognitivos. A cultura digital estimula criatividade, teamworking, criação coletiva e a técnica do "faça você mesmo". Para essas atividades, além das habilidades "superiores da mente" relacionadas à inteligência, tais como lógica, capacidade associativa, resolução de problemas, análise e tomada de decisão, são necessárias habilidades que tradicionalmente não são consideradas cognitivas, tais como as habilidades sensório-motoras, perceptivas, afetivas e sociais. Podemos afirmar que a comunicação digital exige saberes teóricos, inteligência prática, capacidade de conexão/associação, criatividade e outras habilidades e recursos. Ou seja, demanda um engajamento ativo que mobiliza o corpo e o contexto do indivíduo.

Observamos que as práticas comunicativas e sociais da cultura digital têm proporcionado articulações dinâmicas entre humanos, objetos técnicos e ambiente modulando nossas experiências estéticas, cognitivas e subjetivas. Essas modulações produzidas por abalos nas fronteiras entre exterior e interior, natural e artificial, corpo e mente, suscitam o questionamento dos referenciais teórico-metodológicos que fundamentavam essas fronteiras. 


\section{De tecnologias da inteligência a tecnologias que colocam a questão o que é inteligência?}

A palavra inteligência é formada pela raiz legere - do verbo em latim lego -, que significa juntar ou conectar e está relacionada à faculdade de conhecer/compreender o mundo. Embora não exista consenso sobre o que é inteligência ${ }^{5}$, herdamos de nossa tradição, fortemente marcada por pressupostos racionais, a ideia de que o conhecimento verdadeiro deve buscar a essência do objeto. Assim, as chamadas habilidades superiores da mente: o raciocínio lógico, a memória, o domínio sobre as linguagens e a capacidade analítica são as ferramentas primordiais para apreensão e acúmulo de conteúdos. Estes, por sua vez, repousam sobre abstrações isoladas, formas e essências que permanecem no tempo e no espaço, independentes de situações concretas. Desse modo, aprender significa absorver e repetir informações finalizadas, já dadas. A inteligência clássica é descorporificada, uma capacidade de antecipar situações, planejar e resolver problemas.

Estudos das décadas de 1970 e 1980, oriundos de vários campos das ciências cognitivas e, em particular de Biologia Evolutiva, Neurociências e Inteligência Artificial ${ }^{6}$ desafiam o conceito clássico de inteligência. Demonstram que o sistema sensório-motor ocupa a maior parte de nossos cérebros e é resultado de dois bilhões de anos de evolução $(C f$. MORAVEC, 1988). Hans Paul Moravec estima que o processo denominado mente só é possível porque tem como suporte o saber mais antigo e mais potente dos mecanismos sensório-motores: "organismos que não possuem a habilidade de perceber e explorar seus ambientes - como as plantas - não parecem adquirir capacidade de desenvolver inteligência", argumenta Moravec (1988, p. 16).

Por esta perspectiva, a inteligência e a razão não são descorporificadas, ao contrário, apoiam-se firmemente na rocha sólida que é nosso aparato sensório-motor. Como explicam George Lakoff e Mark Johnson. “A razão não é descorporificada [...] ela resulta da natureza

\footnotetext{
5 Para uma maior discussão, consultar STERNBERG, R. \& GRIGORENKO, E. (2003), quando os autores discutem o embate entre os teóricos que apostam na existência de uma inteligência geral (capaz de ser mensurada pelo g-factor) e os teóricos das múltiplas inteligências.

${ }^{6} \mathrm{Na}$ década de 1980, pesquisadores da IA observaram que, se os computadores executam com extrema facilidade tarefas que requerem inteligência tradicional (raciocínio lógico-matemático), há outras atividades que o homem faz sem pensar - como andar, manusear objetos e reconhecer uma pessoa - que são extremamente difíceis de automatizar. Essas observações abriram campo para o estudo das funções sensório-motoras e perceptivas no funcionamento da mente.
} 
de nossos cérebros, corpos e experiência corporal [...] a própria estrutura da razão advém dos detalhes de nossa corporificação.". 7 (1999, p. 4).

Compartilhando desta perspectiva que entende que inteligência e comportamento não são resultados de representações do mundo, mas processos emergentes da dinâmica das interações concretas com o mundo, o psicólogo cognitivo Jerome Bruner destaca a importância da cultura - inseridos aí os objetos técnicos, afetos e sociabilidades - e cunha a expressão "tesouros de ferramentas da cultura" [culture's treasure of kit tools]. Bruner defende que a inteligência se desenvolve dentro das possibilidades de acoplamento entre pessoas, objetos e protocolos de uma cultura.

\begin{abstract}
A inteligência de um indivíduo nunca é solo. Ela não pode ser compreendida sem levar em conta sua referência a livros, cadernos, programas de computador, bancos de dados, ou, o mais importante de todos, sua rede de amigos, colegas ou mentores em quem se apoiar para ajuda ou conselhos ${ }^{8}$ (BRUNER, 1991, p. 3).
\end{abstract}

Pesquisadores como Donald Norman e Andy Clark enfatizam a importância das interações com outros indivíduos e com os objetos técnicos para o processo cognitivo. Ressaltam ainda que objetos técnicos cognitivos não são apenas computadores e gadgets sofisticados. Norman denomina de artefatos cognitivos qualquer ferramenta que auxilie a mente (1993, p. 4) o que inclui tanto artefatos materiais, como o papel, o lápis, a calculadora, o computador, quanto artefatos mentais, como a linguagem, a lógica e a aritmética. Norman destaca ainda a importância da cooperação social para as atividades cognitivas, num processo que denomina de inteligência distribuída:

\begin{abstract}
As pessoas operam como um tipo de inteligência distribuída, na qual grande parte de nosso comportamento inteligente resulta da interação de processos mentais com os objetos e determinações do mundo e na qual muitos comportamentos ocorrem por meio de um processo cooperativo com outrem (NORMAN, 1993, p. 146).
\end{abstract}

Andy Clark resume assim os diversos fatores que compõem a complexidade da mente humana:

\footnotetext{
${ }^{7}$ Do original: Reason is not disembodied [...] but arises from the nature of our brains, bodies, and bodily experience $[\ldots]$ the very structure of reason itself comes from the details of our embodiment.

${ }^{8}$ Do original: An individual's working intelligence is never "solo." It cannot be understood without taking into account his or her reference books, notes, computer programs and data bases, or most important of all, the network of friends, colleagues, or mentors on whom one leans for help and advice.
} 


\begin{abstract}
A ideia central de mente, ou melhor o tipo especial de mente associada com as relações de alto-nível, distintivas da espécie humana, emerge a partir da colisão produtiva de múltiplos fatores e forças - alguns corporais, alguns neurais, alguns tecnológicos e alguns sociais e culturais (2001, p. 141).
\end{abstract}

Assim, ponderamos que se as TIC podem ser consideradas tecnologias da inteligência, seria menos por serem tecnologias da inteligência per si, e antes por serem tecnologias que colocam em questão o que é inteligência. Ao mobilizar um repertório amplo de habilidades cognitivas, a comunicação digital demanda conceitos de inteligência e cognição que incluam não apenas a razão, mas também sensações, afetos, inteligência prática e interações sociais e problematize o conceito de meio e o papel dos objetos técnicos em nossos processos cognitivos e subjetivos.

O conceito de cognição atuada, de Francisco Varela (1990), é uma perspectiva teórica instigante para indagar sobre as modulações subjetivas emergentes de nossas articulações com os objetos técnicos hoje. Por sua atuação como biólogo, Varela explica o modo como inteligência e razão se constituem a partir de nossos sistemas biológicos e a história evolutiva da espécie, associando-as à nossa história cultural. A perspectiva de Varela parte de uma proposta transdisciplinar, ou seja, parte do pressuposto de que o real é hipercomplexo, não redutível aos métodos deterministas e reducionistas da ciência moderna. Márcio Tavares D'Amaral (1995, p. 91) explica que a abordagem transdisciplinar busca superar as dicotomias entre sujeito e objeto, mente e corpo, realismo e idealismo, natural e artificial, interior e exterior, como modo de compreender o caráter complexo e múltiplo do real. Para argumentar de que modo a cognição atuada é uma superação (e alternativa) às posições filosóficas dicotômicas do realismo e do idealismo, Varela explica a cognição por meio da metáfora "do ovo e da galinha" (1990, p. 82-83).

$\mathrm{O}$ autor sugere que pensemos como opera o sentido da visão. O que surge primeiro? O mundo (exterior) ou a imagem em nossa mente (interior)? A resposta do ponto de vista "realista" é pensada pelas designações das tarefas estudadas: "a recuperação da forma a partir da sombra"; ou "da profundidade a partir do movimento" ou "da cor a partir da iluminação". O ponto de vista realista representa a posição da galinha, ou seja, "o mundo exterior é composto por regras fixas; precede a imagem que projeta para o sistema cognitivo cuja tarefa consiste em apreendê-lo - o mundo - de modo adequado" (1990, p. 83). 
Tentemos imaginar agora a posição do ovo, ou seja, o ponto de vista "idealista": "o sistema cognitivo cria o seu próprio mundo e toda a sua aparente solidez assenta sobre as leis internas do organismo" (idem).

A abordagem da cognição atuada propõe assim uma via intermediária, para além desses dois extremos. Nas palavras de Varela:

\begin{abstract}
Abrindo caminho para além desses dois extremos e definindo (como qualquer agricultor sabe) o ovo e a galinha se definem um ao outro e são correlativos [...] É esta ênfase sobre a codeterminação (para além da galinha e do ovo) que distingue o ponto de vista da enação [atuação] de qualquer forma de construtivismo ou de neokantismo biológico (VARELA, 1990, p. 83).
\end{abstract}

A cognição atuada é um paradigma que explica que o processo cognitivo é intrínseco à própria vida. É uma prerrogativa do corpo e se articula à nossa história biológica, cultural e psicológica. Varela, Thompson e Rosch defendem da seguinte maneira a importância do corpo para o processo cognitivo:

Ao usar o termo corporalizada pretendemos destacar dois pontos: primeiro, que a cognição depende dos tipos de experiência que surgem do facto de se ter um corpo com várias capacidades sensório-motoras e, segundo, que estas capacidades sensório-motoras individuais se encontram elas próprias mergulhadas num contexto biológico, psicológico e cultural muito mais abrangente (VARELA; THOMPSON e ROSCH, 2001, p. 226).

Nossa fisiologia do corpo depende de estruturas biológicas desenvolvidas ao longo da história evolutiva da espécie. Assim como depende da cultura em que estamos inseridos, e como cada indivíduo é um ser único, depende do substrato psicológico. Varela associa o processo cognitivo a tempos distintos do estágio de nosso ser: estamos associados ao tempo evolutivo da biologia por meio das estruturas e fisiologia de nosso corpo, estamos associados a um tempo histórico pela interação com nossa cultura e a um tempo individual e presente, o da vida e do corpo.

\title{
Considerações finais
}

Assim, se as TIC podem ser pensadas como tecnologias da inteligência não é somente porque colocam à nossa disposição incontáveis bancos de dados ou potencializam a produção, armazenamento e distribuição de conteúdos como propunham pesquisadores do início da cibercultura (LÉVY, 1993). A comunicação multimodal, o estímulo ao teamworking, à 
criatividade e ao "faça você mesmo" mobilizam um conjunto de habilidades corporais, sociais e afetivas, irredutíveis ao conceito de inteligência (enquanto habilidades superiores da mente), que nos fazem repensar as articulações entre corpo e mente (e, consequentemente, o conceito de humano) e a construção de nossa subjetividade como inerentemente associada aos objetos técnicos e a novas configurações espaço-temporais. Por esse motivo, recorremos ao conceito de cognição atuada, de Varela (1990), para buscar compreender essas modulações intelectivas, que além dos tradicionais preceitos de lógica, acolhe também o corpo, afetos, objetos técnicos e sociabilidade. O conceito de cognição atuada permite compreender o caráter coletivo e distribuído do processo intelectivo. Uma inteligência que se produz com o contato do corpo e da cultura. Entende-se assim que as práticas de comunicação contemporâneas operam em áreas de sombreamento de fronteiras corpo/mente, interior/exterior, orgânico/maquínico, natural/técnico, sujeito/objeto. Quando se opera nas áreas fronteiriças, entende-se que não há polarização entre pares pretensamente dicotômicos. Antes, há codeterminação, modulação conjunta entre sujeito e objeto, natureza e ambiente técnico: "O mundo e o sujeito perceptor se especificam uns aos outros" (VARELA; THOMPSON; ROSCH, 2001, p. 226).

Ao esgarçar as fronteiras entre interior e exterior, biológico e maquínico, natural e técnico, a cultura digital alinha-se com o modo de operar das narrativas de ficção científica.

Desse modo, observamos que as modulações de nossa subjetividade no lidar com os objetos técnicos nos relacionam com experiências da ficção científica por duas razões. Primeiro, temos a sensação de viver num mundo de ficção científica, pois os artefatos digitais colocam no dia-a-dia uma estética futurística que parece sair das histórias de FC. Na verdade, algumas saem de fato. A NASA criou uma página ${ }^{9}$ que atualiza as invenções de Star Trek (Jornada nas Estrelas) à medida que elas vão virando realidade. Como exemplos, podemos citar o ipad (que também foi previsto no filme 2001 - uma odisseia no espaço), um fone de ouvido tipo Bluetooth e o celular. Voltando um pouco mais atrás, no romance 1984 (1948), de George Orwell, câmeras de TV espalhadas por toda a cidade são usadas para vigiar a população. Outra antecipação de George Orwell é um aparelho chamado speakwrite, que transforma o que o protagonista diz em texto, recurso comum hoje em qualquer smartphone.

\footnotetext{
${ }^{9}$ Link: http://www.nasa.gov/topics/technology/features/star_trek.html.
} 
Em segundo lugar, a ficção científica sempre desafiou nossas fronteiras ontológicas e epistemológicas (BUKATMAN, 1998, REGIS, 2012) mais garantidas com suas histórias sobre máquinas inteligentes, seres mutantes, viagens no tempo, realidades alternativas, universos paralelos. As utopias, distopias e heterotopias narram outras configurações espaçotemporais e nossos devires, outras possibilidades de nós mesmos. Essas joias narrativas, que encantam e inquietam nossa imaginação, são potentes modulações de nossa subjetividade contemporânea.

\section{Referências}

BRUNER, Jerome. The narrative construction of reality. Critical Inquiry, n. 17, p. 1-21, 1991.

BUKATMAN, Scott. Terminal Identity: the virtual subject in post-modern science fiction. 4 ed. Duke University Press: 1998.

CLARK, Andy. Mindware: an introduction to the philosophy of cognitive science. New York/Oxford: Oxford University Press, 2001.

D`AMARAL, Márcio Tavares. O homem sem fundamentos: sobre linguagem, sujeito e tempo. Rio de Janeiro: Editora UFRJ / Editora Tempo Brasileiro, 1995.

GUATTARI, Félix. Caosmose. Rio de Janeiro: Ed. 34, 1992.

GIBSON, William. Neuromancer. São Paulo: Aleph, 1991 [1984].

HAYLES, Katherine. How we became posthuman. Chicago e Londres: Universidade de Chicago, 1999.

JOHNSON, Steven. Cultura da Interface: como o computador transforma nossa maneira de criar e comunicar. Rio de Janeiro: Jorge Zahar, 2001.

KASTRUP, Virgínia. A invenção de si e do mundo. Uma introdução do tempo e docoletivo no estudo da cognição. BeloHorizonte: Autêntica, 2007.

LAKOFF, George, JOHNSON, Mark. Philosophy in the flash. Nova York: Basic Books, 1999.

LATOUR, B. Reassembling the social: an introduction to the Actor-Network-Theory. Oxford: Oxford University Press, 2005.

LEROI-GOURHAN, André. Milieu et techniques. Paris: Albin Michel, 1945.

LÉVY, Pierre. Cibercultura. São Paulo: Ed. 34, 1999. 
LÉVY, Pierre. As Tecnologias da Inteligência: o futuro do pensamento na era da informática. Rio de Janeiro: Editora 34 Letras, 1993.

MANOVICH, Lev. Remixing and Remixability, 2005. Disponível em http://www.manovich.net/DOCS/Remix_modular.doc.

MAZLISH, Bruce. The fourth discontinuity: the co-evolution of humans and machines. Nova Haven and London: Yale University Press, 1993.

MORAVEC, Hans Paul. Mind Children. Cambridge: Harvard University Press, 1988.

NORMAN, Donald. Things that make us smart. Cambridge: Perseus Books, 1993.

ORWELL, George. 1984. São Paulo: Cia das Letras, 2009 [1948].

PEREIRA, Vinicius. G.A.M.E.S. 2.0 - Gêneros e Gramáticas de Arranjos e Ambientes Midiáticos Mediadores de Experiências de Entretenimento, Sociabilidades e Sensorialidades. In: Anais do XVII Encontro da Compós, 2008. São Paulo: UNIP, junho de 2008.

REGIS, Fátima. Nós, Ciborgues: tecnologias de comunicação e subjetividade homemmáquina. Curitiba: Champagnat, 2012.

SIMONDON, Gilbert. On the Mode of Existence of Technical Objects. Translated from the French by Ninian Mellamphy. University of Western Ontario, 1980.

SOARES, Letícia Perani. "O maior brinquedo do mundo": a influência comunicacional dos games na história da interação humano-computador. 2016. 180 folhas. Tese. (Doutorado em Comunicação). Programa de Pós-Graduação em Comunicação, UERJ, Rio de Janeiro, 2016.

StERnBERG, Robert and GRIGOREnKO, Elena (ed). The Psychology of Abilities, Competencies, and Expertise. Cambridge: Cambridge University Press, 2003.

TURING, Alan. "Computing Machinery and Intelligence”. In: BODEN, Margaret A. (ed.) The philosophy of Artificial Intelligence. Oxford University Press, 1990.

VARELA, Francisco. Conhecer: as ciências cognitivas, tendências e perspectivas. Lisboa: Instituto Piaget, 1990.

VARELA, Franscisco; THOMPSON, Evan T.; ROSCH, Eleanor. A Mente Corpórea: ciência cognitive e experiência humana. Lisboa: Instituto Piaget, 2001. 


\section{Filmes e Séries de TV}

2001, uma odisséia no espaço / 2001, a space odissey. EUA: MGM,1968. Dir: Stanley Kubrick. 161 min.

Jornada nas estrelas / Star Trek- EUA: Paramount (1964-1966). Criação de Gene Rodenberry. Tron - uma odisséia eletrônica / Tron. EUA: Walt Disney Productions, 1982. Dir.: Steve Lisberger. 96 min. 